\title{
DISCURSO DE ABERTURA DO I SEMINÁRIO BRASILEIRO DE ESCRITA DRAMÁTICA ${ }^{1}$
}

\author{
Paulo Ricardo Berton \\ Professor do Curso de Artes Cênicas no Departamento de Artes (UFSC) \\ E-mail: pauloricardoberton@gmail.com
}

Em primeiro lugar, sejam muito bem-vindos ao I Seminário Brasileiro de Escrita Dramática: Reflexão e Prática. Incertos quanto à repercussão da nossa iniciativa, estivemos sempre cientes de que o objetivo maior era o de juntar dramaturgos e pesquisadores da escrita dramática sob o mesmo teto, a fim de alcançar um nível elevado de discussão, problematizando as questões mais cruciais da escrita teatral no Brasil. Acredito que este objetivo foi alcançado. Foram convidados participantes de diferentes realidades geográficas e de variados contextos culturais, o que só vem a enriquecer o diálogo e a troca de experiências neste campo do saber.

Se alguém se sentiu incomodado com o termo 'dramática' no título do nosso evento, a provocação foi proposital. Ao finalizar a preparação de uma aula, na qual seriam discutidos os textos Ruínas, de Sarah Kane; Apenas o Fim do Mundo, de Jean-Luc Lagarce e Anjos na América, de Tony Kushner, constatei minha discordância com uma afirmação universalista de Hans-Thies Lehmann. O professor da Universidade de Frankfurt, em seu texto já canô- nico, Teatro Pós-dramático, afirma que, se o novo texto teatral, por um lado, reiteradamente, constitui-se como uma forma verbal, por outro, é considerado, de forma praticamente generalizada, "[...] não mais dramático."2 (Lehmann, 1999 , p. 13 , tradução nossa). Por isso, entendo como fundamental levantar algumas querelas do teatro contemporâneo, que nos fazem retroceder, de forma patética (no sentido de ridículo), ao embate entre antigos e modernos, iniciado nos primeiros anos do século XVII, na França.

O que deve ficar claro, antes de mais nada, principalmente pelo tom incisivo da minha fala, é que os petardos lançados pretendem abalar uma ideia hegemônica de teatro, que, por acaso, vem a ser aquela que corrobora a constatação de Eric Bentley, publicada no prefácio do seu livro The Playwright as Thinker, de 1945: "Este livro é sobre o dramaturgo, o homem esquecido dos palcos de hoje"3 (Bentley, 1955, p. XIV, tradução nossa).

A ausência de pluralidade é nefasta em qualquer campo do saber, pois anula o pensamento dialético e sacraliza uma mentalidade

\footnotetext{
1 O I Seminário Brasileiro de Escrita Dramática: Reflexão e Prática foi realizado entre 11 e 14 de novembro de 2015, em Florianópolis, e organizado pelos professores doutores Paulo Ricardo Berton (UFSC), Manoel Levy Candeias (Escola Superior de Artes Célia Helena), Rafael Ary (UFSC) e Elisana de Carli (UFSC), com o patrocínio da Fapesc e da Secretaria da Cultura da UFSC.

2 "Zugleich ist der neue Theatertext, der seinerseits immer wieder seine Verfassung als sprachliches Gebilde reflektiert, weithin ein 'nicht mehr dramatischer' Theatertext”. (Lehmann, 1999, p. 13).

3 "This book is about the playwright, the forgotten man of the modern stage". (Bentley, 1955, p. XIV).
} 
autoritária e impositiva. A dominação hierárquica de qualquer um dos componentes do espetáculo teatral: autor, encenador ou ator, poderia citar todos os outros que compõem uma arte colaborativa por natureza, apenas gera discórdia e insatisfação. Por isso, a indignação que vem do lado, hoje marginal, do outsider que reivindica o equilíbrio e a harmonia na equação teatral, num outro contexto, estaria também se posicionando de forma crítica, caso o lugar ocupado na gangorra fosse o de cima.

O drama necessita do teatro, apesar de o teatro não necessitar do drama. Quanto a isso, imagino que a maioria de nós esteja de acordo. O drama somente se concretiza na cena. Por esta razão que o autor escolhe este gênero, quando poderia ter escolhido se expressar de uma forma majoritariamente narrativa ou lírica. É notório que cada um dos gêneros se adequa melhor a determinadas características temáticas, espaciais e temporais. A longa trajetória de Ulisses, de volta ao lar, não causaria o mesmo efeito num poema de cinco linhas ou numa peça de uma hora. Assim, nós dramaturgos, precisamos do teatro. No entanto, quando Josette Féral menciona Michael Fried, dizendo que o sucesso e a sobrevida das artes dependem da faculdade de por em xeque o teatro, um frio percorre a nossa espinha. Tendo sido ameaçada pelo cinema, a partir do início do século $\mathrm{XX}$, a arte do teatro, porém, nunca sofreu um ataque tão vigoroso e direto como aquele advindo da arte da performance. $\mathrm{O}$ cinema nunca precisou aniquilar o teatro para existir. Negar os elementos constituintes básicos da arte teatral como a mimese, a ficcionalidade e a visibilidade, nunca esteve na agenda dos teóricos e praticantes da sétima arte. Entretanto, como afirma Josette Féral: "A performance não gosta do teatro e desconfia dele. O teatro, por sua vez, não gosta da performance e se distancia dela. Existe entre essas duas artes uma desconfiança recíproca". (Féral, 2015, p. 135).

O que mais intriga é o fato de que, apesar de ser uma arte cênica, a performance não é uma arte da representação. Para Féral, "[...] tudo coloca a performance do lado das artes plásticas: sua origem, sua história, suas manifestações, seus lugares, seus artistas, seus objetivos, sua concepção de arte, sua relação com o público" (Féral, 2015, p.135). Por que, então, querer matar o teatro? Nem Aristóteles, que privilegiava a tragédia em detrimento da comédia, instigava o desaparecimento desta última! Para mim, o que está em jogo é uma questão de hegemonia, ou, para usar a terminologia do teórico Raymond Williams, uma disputa para ocupar o papel de cultura dominante, relegando o outro, assim, ao papel de cultura residual. Esta luta pelo poder traz, no seu bojo, terminologias, que, num exame mais minucioso, já fizeram parte do teatro em dado momento histórico, porque é exatamente a a-historicidade que o pensamento pós-moderno busca estabelecer, conforme ilustrado no conceito de fim da história do teórico neo-liberal Francis Fukuyama.

Se o teatro corre este risco de extinção, o que dizer do drama? Em primeiro lugar, o termo drama abarca uma pletora imensa de possibilidades, que vai desde a farsa medieval, até o metateatro de Pirandello, passando pelo drama pretensamente absoluto de Racine e o drama aberto de Jelinek. O próprio drama grego clássico já exibia tanto a mistura dos gêneros literários - o narrativo, nos mensageiros, o lírico, no coro e o dramático, nos diálogos - quanto o que se intitula hoje de 
performativo, através da parábase na comédia antiga. A ideia de que o conflito intersubjetivo - sustentáculo do drama - não reflete o homem contemporâneo, e de que, por esta razão, o mundo fechado do drama absoluto estaria em desacordo com a realidade, parece-me adequada aos propósitos teóricos do professor $A$ ou do pensador $B$, mas continua presente, de forma bastante eficaz, em diálogos dos autores que eu citei no início da fala, como, Kushner (2005, p. 35, tradução nossa) por exemplo:

- JOE - Eu votei no Reagan.

- LOUIS - Votou mesmo?

- JOE - Duas vezes.

- LOUIS - Duas vezes? É...ah, garoto.

Um republicano gay então.

- JOE - O que que tu disse?

- LOUIS - Nada, esquece.

- JOE - Eu não sou....Deixa pra lá.

- LOUIS - Republicano? Não é republicano? Ou...

- JOE - O que?

- LOUIS - O que?

- JOE - Não sou gay. Eu não sou gay.

- LOUIS - Ah. Foi mal. ${ }^{4}$

A ideia de que o drama possui regras que fazem dele um gênero literário específico, além da óbvia necessidade da completude cênica, assusta os incautos e irrita os pós-modernos. Lajos Egri, em The Art of Dramatic Writing, diz:

A gente sabe que existem regras pra comer, caminhar e respirar; sabemos que há regras na pintura, na música, na dança, pra voar e para construir pontes; sabemos que há regras para todas as manifestações da vida e da natureza - por que, então, a escrita seria a única exceção?"5 (Egri, 2004, p. xix, tradução nossa).

Alguém duvida do cuidadoso trabalho de escrita de Lagarce, daqueles que a gente chama de $99 \%$ de transpiração e $1 \%$ de inspiração, quando contrapõe duas linguagens contrastantes para criar uma fricção entre o mundo poético de Louis, o protagonista e o mundo banal e pragmático de Suzanne, sua irmã?

LOUIS - ...para anunciar, dizer, apenas dizer, a minha morte próxima e irremediável, anunciá-la eu mesmo, ser o seu único mensageiro, e parecer - talvez o que sempre quis, quis e decidi, em todas as circunstâncias e desde os tempos mais longínquos que eu ouso me lembrar - e parecer uma vez mais poder decidir, me dar e dar aos outros, e a eles, mais precisamente, você, vocês, ela, e ainda os que não conheço (tarde demais e paciência), me dar e dar aos outros uma última vez a ilusão de ser responsável por mim e de ser, até nesta situação extrema, senhor de mim mesmo.

PRIMEIRA PARTE

Cena 1

SUZANNE - É a Catarina. Ela é a Catarina. Catarina, Luiz. Luiz. Catarina. (Lagarce, 2006, p. 24-25).

4 - JOE - I voted for Reagan.

- LOUIS - You did?

- JOE - Twice.

- LOUIS - Twice? Well, oh boy. A Gay Republican.

- JOE - Excuse me?

- LOUIS - Nothing.

- JOE - I'm not... Forget it.

- LOUIS - Republican? Not Republican? Or...

- JOE - What?

- LOUIS - What?

- JOE - Not gay. I'm not gay.

- LOUIS - Oh. Sorry.

5 "We know there are rules for eating, walking, and breathing; we know there are rules for painting, music, dancing, flying, and bridge building; we know there are rules for every manifestation of life and nature - why, then, should writing be the sole exception?" (Egri, 2004, p. xix). 
A consequência da discussão apresentada é que herdamos um preconceito muito grande para com o teatro e para com o drama. Espremidos entre um teatro de caráter comercial, que prioriza o entretenimento puro e um teatro (que nem de teatro mais quer ser chamado) que afasta o público através de espetáculos herméticos e literalmente agressivos, o teatro dramático busca a sobrevivência numa luta, muitas vezes, desigual, conseguindo ser, talvez, a última possibilidade do que se entende por teatro engajado, já que dos outros dois supracitados, um aliena e o outro advoga a impossibilidade do sentido. Por esta razão, o drama não encontra lugar na academia brasileira, sendo desconsiderado nos cursos de letras pela sua permissividade subversiva e sendo rechaçado pelos cursos de artes cênicas por seu conservadorismo demodé. Nós, dramaturgos, gargalhamos desta franca contradição de uma impossibilidade ontológica. Em se falando das produções teatrais, a hegemonia do corpo escorraçou o texto dramático, preferindo as criações soltas do instante eterno, as inspirações vagas de cunho neo-romântico ou mesmo as indignações panfletárias por um mundo melhor. A maioria dos, já lugares-comuns, processos colaborativos tratam o dramaturgo como um mero escriba das ações e das imagens, cuja autonomia é boicotada constantemente por outros membros do processo que se julgam tão aptos a opinar na construção do texto teatral quanto aquele que para aquilo estudou, preparou-se e guardou uma respeitosa experiência. As publicações na área são pífias, reflexo de um desinteresse total dos leitores, devido à aplicação de um currículo básico perverso nas escolas brasileiras, que passa longe do drama, preferindo privilegiar as literaturas narrativas ou líricas, ou então, no encolhimento da carga horária de artes, muitas vezes, tendo o teatro que ser preterido em prol de outra manifestação artística. Quando este público chega à idade adulta, o conhecimento do teatro dramático é tão nulo (sem falar que o do próprio teatro é quase inexistente) que o primeiro contato os distancia ou nunca acontece. Felizmente, alguma luz no fim do túnel existe. Assim como um pequeno número de iniciativas isoladas passa a oferecer o estudo da artesania da escrita dramática, surge o interesse de pessoas pelo desenvolvimento desta profissão, enxergando a possibilidade de trabalho em companhias teatrais que respeitem e partam do texto dramático ou, até mesmo, em outros meios que necessitem do conhecimento do drama, seja na redação de roteiros para cinema ou scripts para séries de televisão.

A batalha é grande e cansativa. Construir o sistema para poder usufruir dele frustra e desanima. No entanto, ao ver cada um de vocês aqui sentados na plateia, numa quarta-feira abafada de novembro, não necessariamente concordando - e espero que não mesmo, para termos alimento para os debates que virão, a partir destas minhas ideias e das outras que surgirem ao longo do evento - mas, o mais importante, prestando atenção no que está sendo dito, tranquilizo-me com a certeza de que os voluntários para esta linha de frente se multiplicam, e que a escrita dramática recupera sua importância, respeito e reconhecimento em todas as instituições que mencionei, sejam elas de caráter público ou de livre associação.

O meu sincero agradecimento a todos que toparam esta empreitada vai pela voz da personagem lan, no sublime final da peça Ruína, da autora inglesa Sarah Kane, uma fábula 
com início, meio, fim, mimesis, conflito, terror e piedade. Um texto, apocrifamente, 'contemporâneo'.

Cate entra trazendo um pouco de pão, uma salsicha enorme e uma garrafa de gim. Tem sangue escorrendo das suas pernas.

CATE - Tu tá sentado embaixo dum buraco.

IAN - Eu sei.

CATE - Vai ficar molhado.

IAN - Uhum.

CATE - Seu idiota estúpido.

Ela puxa um lençol da cama e se enrola com ele. Ela senta perto da cabeça de lan. Ela come da salsicha e do pão, depois engole tudo com o gin. Ian fica escutando. Ela dá de comer pra lan com a comida que sobrou. Ela dá de beber pra lan com o gin. Ela termina de alimentar lan e se senta longe dele, se encolhendo pra se esquentar. Ela bebe o gin. Ela chupa o polegar. Silêncio. Chove.

IAN - Obrigado.

Blecaute.

(Kane, 2001, p. 60-61, tradução nossa).

Referências

LAGARCE, J.L. Apenas o Fim do Mundo. Trad. Giovana Soar. São Paulo: Aliança Francesa: Consulado Geral da França em São Paulo: Imprensa Oficial do Estado de São Paulo, 2006. 216 p. (Coleção Palco sur Scène).

EGRI, L. The Art of Dramatic Writing. New York: Touchstone, 2004. 316 p.

KUSHNER, T. Angels in America. New York: TCG, 2005. 294 p.

LEHMANN, H. Postdramatisches Theater.
Frankfurt am Main: Verlag der Autoren, 1999. $506 \mathrm{p}$.

BENTLEY, E. The Playwright as Thinker. New York: Meridian, 1955. 314 p.

KANE, S. Complete Plays. London: Methuen, 2001. 268 p.

FERAL. J. Além dos Limites: Teoria e Prática do Teatro. Trad. Jacó Guinsburg et al. São Paulo: Perspectiva, 2015. 403 p. 